\title{
Spontaneous Rupture of Splenic Artery Aneurysm in Pregnancy
}

\author{
Şükrü Arslan', Erdem Karadeniz', Abdürrahim Çolak², Ömer Erkan Yapça \\ 'Department of General Surgery, Atatürk University School of Medicine, Erzurum, Turkey \\ ${ }^{2}$ Department of Cardiovascular Surgery, Atatürk University School of Medicine, Erzurum, Turkey \\ ${ }^{3}$ Department of Obstetrics and Gynecology, Atatürk University School of Medicine, Erzurum, Turkey
}

\begin{abstract}
Introduction: Splenic artery aneurysm (SAA) is a rarely seen disease but with a high probability of rupture in pregnancy cases. Once a rupture occurs, both the mother's and the fetus's lives are at risk. It is rather difficult to establish a diagnosis under emergency conditions because it may be confused with obstetric pathologies.

Case Report: A 25-year-old, 24-week pregnant patient was admitted to the emergency department with an arterial blood pressure of $30 / 20 \mathrm{mmHg}$, a filiform pulse, and with no sign of trauma upon physical examination. An ultrasonography scan revealed pregnancy with negative fetal heart beats (FHA). The hemoglobin of the patient was $4.2 \mathrm{~g} / \mathrm{dL}$. The patient had undergone explorative laparotomy, with the preliminary diagnosis of intrauterine dead fetus. The patient was diagnosed with SAA. Because the patient had diffuse infarction in the spleen and severe bleeding from the uterus, she underwent splenectomy and total abdominal hysterectomy. The patient was discharged with cure on the 5th postoperative day.

Conclusion: We aimed to emphasize the fact that a SAA may have developed in pregnant women who apply to the emergency service department with complaints of stomachache and hypotensive findings without a medical record involving any trauma and that taking rapid action in such cases is something to be kept in mind by physicians.
\end{abstract}

Keywords: Pregnancy, splenic artery aneurysm, spontaneous rupture

Received: 19.01.2016 Accepted: 18.02.2016 Available Online Date: 14.06.2016

\section{Introduction}

SAA is the most prevalent type among visceral artery aneurysms (65\%), and the probability of a rupture occurrence increases with age $(1,2)$. An SAA rupture also seen without any medical record involving a trauma in pregnancy can often be camouflaged by other obstetric pathologies. Although rarely seen, the SAA rupture may cause mortality in pregnant women at a rate of 70\%, and establishing an early diagnosis in this case could be life-saving (3). Patients often apply to the emergency department with complaints of stomachache, dyspnea (difficulty in breathing), hypotension, and findings of shock. Different from the aneurysm treatment detected under elective conditions, a proper fluid replacement and emergency surgical operations during treatment come into prominence when a rupture occurs. Although ultrasonography and computed tomography (CT) are mostly applied at the stage of diagnosis, there may still be no adequate time for an examination. Therefore, we aimed to emphasize in this presentation the fact that an aneurysm rupture may have developed in pregnant women who apply to the emergency service department with complaints of stomachache and hypotensive findings without a medical record involving any trauma and that taking rapid action in such cases is something to be kept in mind by the physician of the emergency service.

\section{Case Report}

Upon determining an intrauterine dead fetus in the epicenter of the 24-week pregnant patient aged 25 years, the epicrisis/ discharge report of the patient revealed that she had been referred to the emergency service. The patient was also determined to have been suffering from diabetes mellitus. When this patient was evaluated in the emergency department, it was seen that she had bradycardic and a filiform pulse with TA: 30/20 mmHg, that there was no finding with respect to any trauma dur-

Address for Correspondence:

Şükrü Arslan, Department of General Surgery, Atatürk University School of Medicine, Erzurum, Turkey

E-mail: drsukruarslan@gmail.com

oCopyright 2016 by Emergency Physicians Association of Turkey - Available online at www.jemcr.org 
ing the physical examination, and that the abdomen was intensely distended. In the USG performed per person, a moderate amount of fluid in the abdomen and a fetal heart activity (FHA) negative pregnancy were reported.

In the laboratory tests studied, Hb was $4.2 \mathrm{~g} / \mathrm{dL}$ and Hct was $13.2 \%$, whereas Plt was $120.10^{3} / \mu \mathrm{L}$, INR was 2.1 , and glucose was reported as $200 \mathrm{mg} / \mathrm{dL}$.

Because the patient was in a pre-ex (TA: 30/20 mmHg, Pulse: bradycardic and filiform, Glasgow coma score: 8 ) state and her consciousness was becoming impaired, an intravenous fluid replacement treatment was started, and she promptly underwent an operation. As there was an acute abdominal clinical condition in the patient, an entry into the lower abdomen through the use of a median incision was performed. During the exploration, it was seen that the uterus was almost 7.5 months pregnantin size and that there was about 4000-5000 mL of defibrinated blood in her abdomen as well as the presence of an active hemorrhage (bleeding) from the upper quadrants of the abdomen. After the blood in the abdomen was removed by extending the incision in the form of an upper abdominal median, it was seen that there was an aneurysm rupture in the splenic artery when a systematic exploration was performed. The hemorrhage was ceased by placing clamps on both sides of the aneurysm (Figure 1). An infarct in the spleen was observed to have developed as well. The ex-infant, whose Apgar score was zero in the zeroth minute along with a lower segment transverse uterine incision, was taken out of the abdomen. The amniotic fluid was discharged. The placenta was normal in appearance. The uterus was in a pastry form; however, there was no apparent hemorrhage. The patient was administered with 40 units of Oxytocin infusion, 10 units of pushed Oxytocin, 5 units of Metilergonovin push, and 4 units of rectal Misoprostol. A Bakri buffer was placed from the incised area into the uterus in a pastry form and then a splenectomy procedure was performed for the spleen in which an infarct had developed.

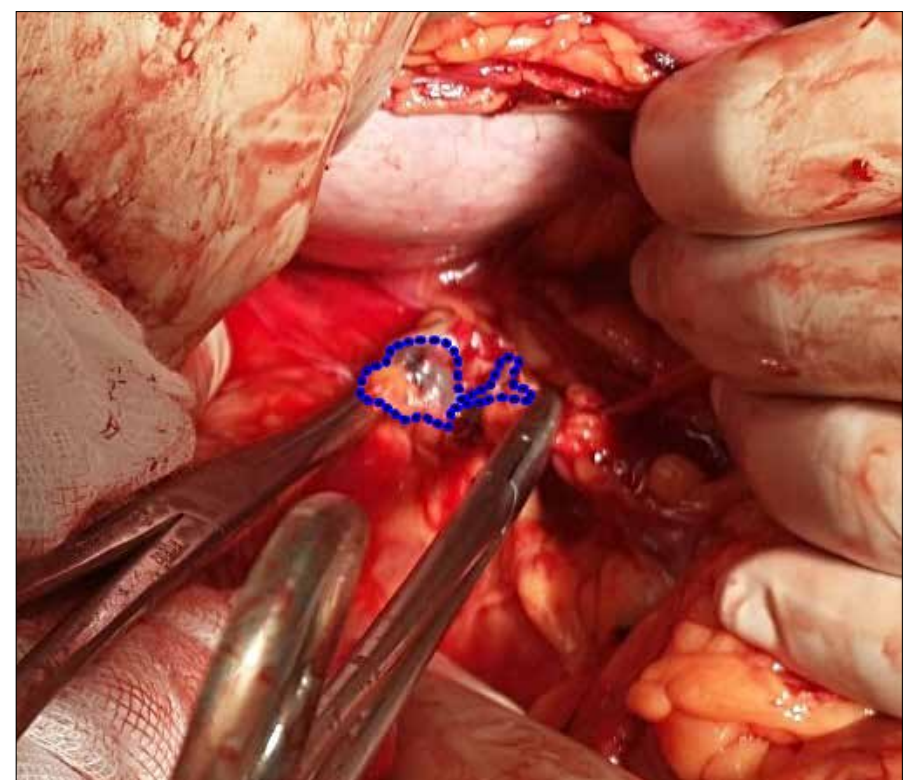

FIGURE 1. Splenic artery aneurysm rupture
Based on the fact that almost $1000 \mathrm{cc}$ of bleeding occurred through the Bakri buffer in the wake of splenectomy and the fact that an active uterine hemorrhage had started within the vagina along with the subcutaneous hemorrhage and the fact that the pastry form of the uterus had become more apparent, the risk of progressing toward a probable disseminated intravascular coagulation (DIC) was taken into consideration; therefore, the patient underwent total abdominal hysterectomy (TAH). Following the hemorrhage control, a piece of Pezzer drain/catheter each was applied onto the Douglas and the splenic area.

The abdominal layers were closed in due form. In the course of the operation, the patient was administered with $1750 \mathrm{~mL}$ of erythrocyte suspension and $1000 \mathrm{~mL}$ of fresh frozen plasma. The patient, having been brought into the intensive care unit with 120/80 mmHg arterial tension, was discharged from the hospital with full recovery on the postoperative 5 th day. The histopathological examination was reported as "ruptured aneurysmal arterial wall." The diameter of the aneurysm was $3.5 \mathrm{~cm}$. (Figure 2a, b). Informed consent was obtained from the patient.

\section{Discussion}

In this article, we presented the case of a spontaneous SAA rupture that had occurred during a 24-week pregnancy. A spontaneous SAA rupture in pregnancy is difficult to diagnose because it may clinically be confused with obstetric emergencies, such as abruptio placentae (placenta decollement) or uterus rupture. A probable SAA rupture is directly proportional to the diameter of aneurysm, and the probability of a rupture is below $10 \%$ in aneurysms with a diameter less than $2 \mathrm{~cm}$. When a rupture occurs, the mortality rate is around 20\%, whereas this percentage goes up to $50 \%$ in pregnant women during their $3 r d$ trimester $(2,4)$. Among the etiological factors for SAA in the literature, we can consider gestational hormonal and hemodynamic changes, atherosclerosis, focal arterial inflammation, pancreatitis, and trauma (5). Because SAA is generally asymptomatic, diagnosis is usually coincidental or made using radiological methods in patients with abdominal left upper quadrant pain. Conventional angiography is the gold standard in the diagnosis of vascular lesions. However, its invasive nature is a disadvantage. Diagnosis can also be easily made with non-invasive methods, such as Doppler USG, CT, MRI, and MRA (6). Because we had insufficient time to evaluate the patient in our case, none of these methods was performed. Fluid was solely determined in the abdomen at bedside USG, and the patient was then taken for surgery.

No surgical treatment is recommended for a randomly detected SAA less than $2 \mathrm{~cm}$ in size, whereas a transcutaneous embolization or a laparoscopic ligation are advised for a symptomatic or asymptomatic SAA larger than $2 \mathrm{~cm}$ in size because the probability of a rupture along with the diameter will be high (7). On the other hand, when a SAA rupture occurs, urgent surgical treatment comes to prominence along with the fluid replacement. Instead of an aggressive fluid replacement in the course of the treatment-because it may lead to hypothermia or coagulation dysfunctions in patients with serious extravasated hemorrhage - a proper fluid replacement should be preferred along with an adequate amount of blood components (8). 


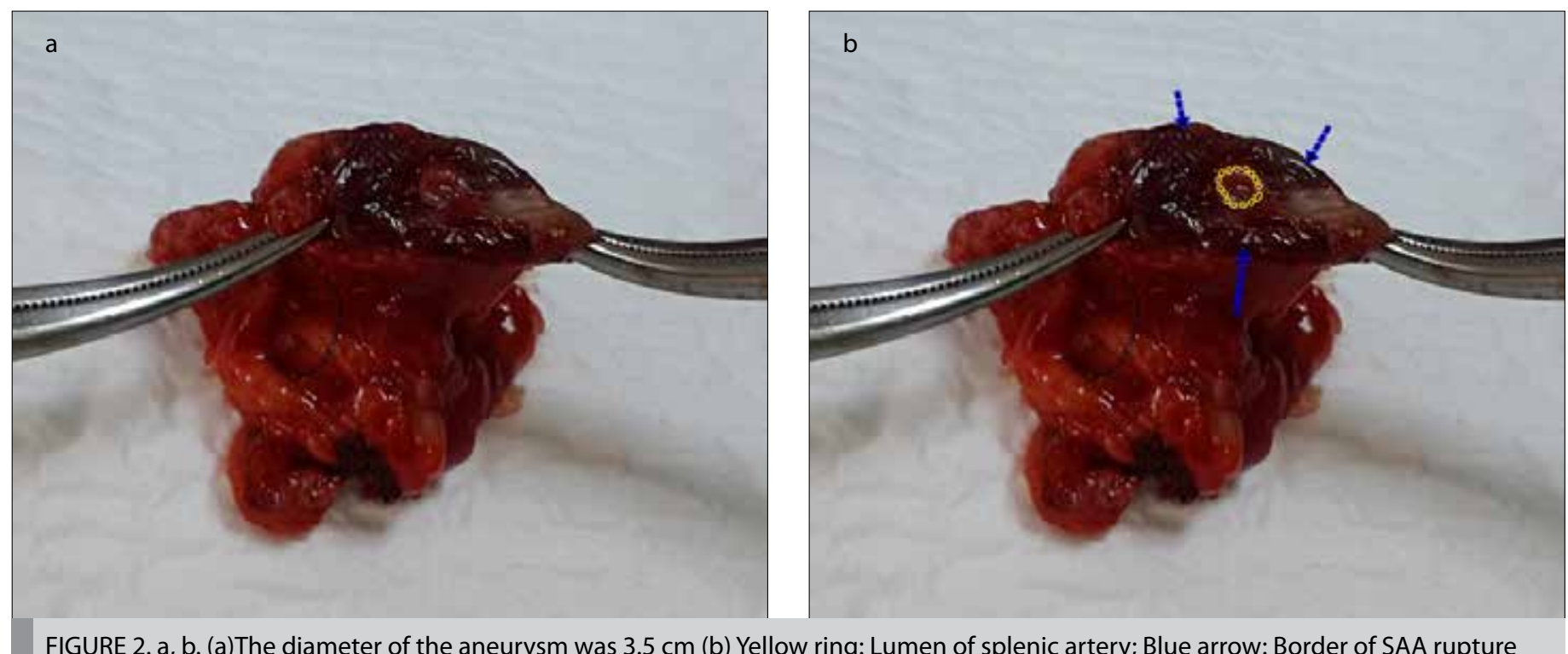

In emergency surgical treatment, a method through which the spleen can be protected and the aneurysm is resected and the artery is ligated, or a method in which the aneurysm is resected and a reconstruction over the artery is performed can be used. Because the hemorrhage in the spleen may continue along with perisplenic collaterals, a splenectomy may not be required in most cases.

In cases with impaired circulation, on the other hand, splenectomy can be added to the procedure (4). However, in recent years, the aneurysm is advised to be closed endovascularly because this is less invasive in emergency hemorrhage cases. In terms of embolic agents, there are options like coil, glue, polyvinyl alcohol particles, stent-graft, and vascular plugs/obturators. In the wake of endovascular treatment, it was reported that there could also be complications observed, such as aneurysm recurrence, abscess, arterial injury, contrasted nephropathy, infarct, and hematoma in the interference area (9).

In our case, the fact that our patient was in her 3rd trimester during her pregnancy, that she also had diabetes mellitus disease, and that the aneurysm was of a diameter of $3.5 \mathrm{~cm}$ were all seen as factors increasing the probability of a rupture development. In the course of the treatment, a fluid therapy along with $1750 \mathrm{~mL}$ of erythrocyte and $1000 \mathrm{~mL}$ of fresh frozen plasma was performed.

Once a splenic arterial aneurysm rupture has occurred, the tiny omentum is first filled with blood, and a tamponade forms, after which an intraperitoneal hemorrhage occurs, and the hemodynamic stability is impaired within almost 6-96 h (10). Also, in our case, because the hemodynamic stability was impaired and an infarct within the spleen had developed, splenectomy was added to the resection of aneurysm. In recent years, endovascular methods are recommended as invasive treatment approaches in patients with emergency hemorrhage aneurysm ruptures. However, our case was not that the patient was detected to have had an aneurysm rupture by means of various imaging methods during the preoperative period, but on the contrary, she was determined to have had an intrauterine dead fetus and underwent an operation at the Clinic of
Obstetrics and Gynecology upon considering an obstetric pathology. The diagnosis of an aneurysm rupture was established only after a lower abdominal median incision had been performed by the Clinic of Obstetrics and Gynecology and only when the incision process was extended in the form of an upper abdominal median, and all the blood in the abdomen was removed in the wake of the intervention in the uterus, which was a procedure performed by us. Moreover, the problem with the patient was not limited to an isolated aneurysm rupture, but also the presence of an intrauterine dead fetus, the loss of vitality in the uterus, and the fact that findings similar to DIC occurred.

The patient was taken under operation in a pre-ex state. She had a hemoglobin level of $4 \mathrm{~g} / \mathrm{dL}$; hence, in such patients, the survival of the patient should be taken into account rather than applying invasive treatments.

In the literature, the mortality rate of the fetus is stated to be $95 \%$ when a rupture occurs during pregnancy (2). In our case, the fetus was lost right in the course of the application to the hospital; however, the mother was discharged from the hospital with full recovery.

\section{Conclusion}

In conclusion, it should be kept in mind by emergency physicians that a spontaneous SAA rupture may likely have occurred in pregnant women with hypotensive findings and complaints of stomachache but with no medical record involving a trauma, and if the clinical parameters of the patient are suitable, endovascular treatment methods should be attempted. However, if the clinical parameters in this type of case are not appropriate, rapid abdominal explorations should not be avoided so as to be able to save the mother's and fetus's lives.

Informed Consent: Written informed consent was obtained from patient who participated in this study.

Peer-review: Externally peer-reviewed. 
Author contributions: Concept Ş.A., A.Ç., Ö.E.Y.; Design - Ş.A.,E.K.; Supervision - Ş.A., A.Ç., Ö.E.Y.; Resource - Ş.A., E.K.; Materials - Ş.A., Ö.E.Y.; Data Collection \&/or Processing - Ş.A., A.Ç., Ö.E.Y.; Analysis \&/or Interpretation - Ş.A., E.K.; Literature Search - Ş.A., Ö.E.Y.; Writing - Ş.A., A.Ç.; Critical Reviews - A.Ç., E.K.;

Conflict of Interest: No conflict of interest was declared by the authors.

Financial Disclosure: The authors declared that this study has received no financial support.

\section{References}

1. Kalko Y, Ugurlucan M, Basaran M, Kafah E, Aydin U, Kafa U, et al. Visceral artery aneurysms. Heart Surg Forum 2007; 10: 4-9. [CrossRef]

2. Özdemir AP ÖR, Işıksalan N, Tola M, Yurdakul M, Ölçer T. İki olgu ile splenik arter ve renal arter anevrizmasının gözden geçirilmesi. J Ist Faculty Med 2011; 74: 32-4

3. Gourgiotis S, Alfaras P, Salemis NS. Spontaneous rupture of splenic artery aneurysm in pregnancy: a case report. Adv Med Sci 2008; 53: 341-3. [CrossRef]
4. Pescarus R, Montreuil B, Bendavid Y. Giant splenic artery aneurysms: case report and review of the literature. Journal of vascular surgery 2005; 42: 344-7. [CrossRef]

5. Abbas MA, Stone WM, Fowl RJ, Gloviczki P, Oldenburg WA, Pairolero PC, et al. Splenic artery aneurysms: two decades experience at Mayo Clinic. Ann Vascular Surgery 2002; 16: 442-9. [CrossRef]

6. Aybar MD, Barut AY, Öztürk A, Demirci I, Tuzcu G. Splenik Arter Anevrizma Rüptürü. İstanbul Tıp Derg 2009; 3: 92-5.

7. Merlo M, Cumino A, Pecchio A, Carignano G, Mioli PR, Cassolino P. Splenic artery aneurysm. Two successfully operated cases. Minerva cardioangiologica 1998; 46: 123-6.

8. Gourgiotis S, Gemenetzis G, Kocher HM, Aloizos S, Salemis NS, Grammenos S. Permissive hypotension in bleeding trauma patients: helpful or not and when? Crit Care Nurse 2013; 33: 18-24. [CrossRef]

9. Yamamoto S, Hirota S, Maeda H, Achiwa S, Arai K, Kobayashi K, et al. Transcatheter coil embolization of splenic artery aneurysm. Cardiovascular Interventional Radiol 2008; 31: 527-34. [CrossRef]

10. Berceli SA. Hepatic and splenic artery aneurysms. Semin Vasc Surg 2005; 18: 196-201. [CrossRef] 